\title{
CARLOS FUENTES EM SUA VARANDA
}

\author{
Wilton Barroso Filho ${ }^{1}$ \\ Denise Moreira Santana ${ }^{2}$
}

\begin{abstract}
Resumo: O presente artigo tem por objetivo apresentar uma visão do modelo jornalístico do autor e romancista Carlos Fuentes e visitar a obra póstuma Federico en su balcón, para refletir sobre aspectos que interligam sua amizade com o escritor Milan Kundera, com considerações feitas a partir do ensaio Milan Kundera: o idílio secreto, e o prêmio González Ruano de jornalismo recebido em 2008 pelo texto jornalístico sobre a obra de Hernán Lara Zavala: Península, península. A possibilidade de análise comparativa entre a defasagem temporal das obras destes autores permite tratar no ambiente estético a particularidade universal da literatura visto pela crônica que persegue um tempo revolucionário de diferentes racionalidades estéticas justapostas.
\end{abstract}

Palavras-chave: Carlos Fuentes. Jornalismo. Literatura.

\section{CARLOS FUENTES ON YOUR BALCONY}

\begin{abstract}
The present article aims to present a vision of the journalistic model of the author and novelist Carlos Fuentes and to visit the posthumous work Federico en su balcón, to reflect on aspects that connect his friendship with the writer Milan Kundera, with considerations made from the Milan essay Kundera: the secret idyll, and the González Ruano prize for journalism received in 2008 by the journalistic text on the work of Hernán Lara Zavala: Peninsula, peninsula. The possibility of comparative analysis between the time lag of the works of these authors allows to treat in the aesthetic environment the universal particularity of the literature seen by the chronicle that pursues a revolutionary time of different aesthetic rationalities juxtaposed.
\end{abstract}

Keywords: Carlos Fuentes. Journalism. Literature.

\section{Introdução}

Carlos Fuentes (1928-2012), escritor, jornalista, ensaísta e diplomata mexicano, foi indiscutivelmente um homem do seu tempo. Apesar de ter nascido no Panamá, sempre teve cidadania mexicana já que era filho de diplomata mexicano. Vive os seus primeiros anos entre Quito, Montevideo,

1 Professor da Universidade de Brasília.

2 Professora da SEEDF e doutoranda em Literatura pela Universidade de Brasília. 
Rio de Janeiro, Washington, Santiago do Chile e Buenos Aires. Volta para o México para cursar Direito e depois ingressar na carreira diplomática. Sua grande obra romanesca revela uma autonomia de pensamento que faz dele um crítico do presente que não deixa de revisitar e refletir sobre o passado.

A obra literária de Carlos Fuentes é vasta, e a sua criação se confunde com o transcurso de sua vida. O jornalista Carlos Fuentes aparece aos poucos, mas já no início dos anos de 1960 militava na revista "Política" 3 . O papel do romance na imprensa é um dos questionamentos de Fuentes que lhe levariam para a prática da crônica jornalística; há nele um desejo quase que manifesto de buscar "o leitor" para o romance. Talvez por isso lhe intrigasse tanto o lugar onde apareciam as matérias sobre o romance, no interior dos jornais, nos chamados Cadernos de Arte e Literatura.

A obra jornalística de Fuentes está quase que totalmente consagrada à literatura crítica, uma leitura sensível, uma crônica da vida comum. O autor se empenha em mostrar o real papel transformador da literatura, entende que ler romances é um meio de formação e esclarecimento para as pessoas. Seus textos jornalísticos, em geral, são leituras de outros romances e análise de ações humanas. As leituras que trazem os artigos de Fuentes são extremamente internacionais e têm uma constante preocupação com o universal. Há em sua leitura uma análise política, que pode ser traduzida por uma maneira mexicana de olhar o mundo, o que transforma cada leitura em um problema global.

\section{Fuentes e Kundera: laços escritores}

Carlos Fuentes teve uma vida atribulada como membro da diplomacia mexicana, inclusive com uma passagem importante pela Organização Mundial do Trabalho. Foi embaixador do México em Paris, momento em que desenvolveu uma aproximação intelectual profunda com o escritor tcheco Milan Kundera; eles se conheceram em Praga, 1968. Durante o período parisiense os dois escritores tinham encontros regulares na Embaixada do México. A aproximação entre eles permitiu uma evocação de

\footnotetext{
${ }^{3}$ A revista Política, Quince días de México y del Mundo, foi uma revista de temas políticos nacionais e internacionais fundada por Manuel M. Pardiñas e circulou entre os anos de 1960-1967 no México. (disponível em: https://www.nexos.com.mx/?p=12764, acesso em janeiro de 2018.)
} 
uma visão literária particular, afinal México ou Praga, pouco importa, se situavam na periferia de um mundo dito civilizado constituído pela Europa Ocidental e a América hispana. Esses encontros são descritos em partes e ou aspectos diversos pelos dois escritores em textos posteriores.

Os encontros em Paris, entre Kundera e Fuentes, deixam marcas profundas em Kundera, ao lê-los reciprocamente, pode-se observar, sobretudo naquilo que falam um do outro, a importância do conceito de idílio, ou seja, por definição a existência de um lugar no mundo onde não haja conflito algum. Ainda que de modo diverso, Kundera e Fuentes trilham um caminho estético de denúncia e/ou sabotagem do mundo idílico, afirmam juntos, e de certa forma reciprocamente, que o idílio é a utopia de todos os tiranos, porque significa a ausência de todos os conflitos.

A arte do romance, de ambos, representa olhares externos aos grandes centros do mundo, o desvio geográfico de narração é ao mesmo tempo da descrição do mundo que funda as convicções profundas de seus narradores. Na voz dos narradores destes dois autores emerge um mundo que deixa de levar em consideração tensões locais para dar lugar a histórias que possuem dimensões universais.

Em sua narrativa literária Fuentes denota a vontade estética por descrever como todas as nossas tragédias latino-americanas têm relações com as tristes ditaduras. Elas partilham da mesma utopia de um mundo sem conflitos onde todos possam viver em paz. A escrita de Fuentes busca não apenas romancear, mas ao mesmo tempo procura ser reflexiva, mostrar que em potência o idílio estará sempre em algum lugar no futuro. Ainda que este futuro não se realize em ato, gera uma dinâmica: trabalho, preparação e justificação do futuro, tornando-se assim uma fonte extremamente perversa de construção de poderes totalitários.

O jornalista Carlos Fuentes deseja mostrar as possibilidades do romance, correlacionando este com a vida real. Seus artigos e crônicas costumam partir de uma grande e ampla cosmovisão do mundo passado e, sobretudo, presente. Um tipo de análise do romance em que emerge a ideia de que este gênero literário não seria apenas uma representação da vida, mas a própria vida com todas as suas significações.

De forma inequívoca praticou “jornalismo literário", mas fez deste um ofício diferenciado, redimensionando o papel da ficção no real e do real na ficção propondo que a ficção seja um meio importante de análise do real, ele 
busca na verdade a descoberta do presente e constrói sua leitura sempre utilizando "o tempo" para esclarecer o presente, sempre com uma original interação com o passado intertextual.

Em sua imensa obra literária ${ }^{4}$ Carlos Fuentes tem uma percepção estética atenta para consolidar o surgimento local de sua voz literária. Em narrativas como Federico en su balcón (2012) ${ }^{5}$, obra publicada no ano de sua morte, Fuentes presenteia seus leitores com um diálogo narrativo entre Nietzsche e um narrador interlocutor que testemunha o drama revolucionário vivido pelos irmãos "Leonardo e Dante Loredano". Em um romance centrado num olhar latino-americano e, portanto, externo ao "centro do mundo". A voz narrativa de Fuentes dialoga com a de Federico Nietzsche, o que metafórica e ironicamente desconstrói alguns supostos heróis da nação e que revela toda a perversão e sofisticação da máquina estatal corrupta, sonegadora e manipuladora; é uma narrativa que mostra como as crenças políticas podem ser vãs.

Crítico das ditaduras latino-americanas dos anos 1970 e 1980, sobretudo depois de viver a Paris de maio de 1968 e também a partir do aprofundamento das suas relações com Milan Kundera torna-se igualmente um crítico do mundo do Leste. Essas posições trazem algumas dificuldades, porque ele não pode ser enquadrado como um pensador da esquerda progressista latino-americana tradicional, mas também de forma alguma, pertence a linha dos conservadores. Foi por vezes ambíguo, mas um defensor do valor universal das mais simples narrativas acerca de um mundo descrito em um realismo com forte sotaque mexicano. Deve-se ousar dizer que Carlos Fuentes é universal porque seus personagens são localmente reais, mas quase sempre ligados em insuspeitas complicações advindas de um não muito claro poder central, que sabota e impede os avanços da sociedade mexicana.

\footnotetext{
${ }^{4}$ Em livre descrição cronológica dos romances, ensaios e contos da obra de Carlos Fuentes têm-se: Los Días Enmascarados, 1954, La Región Más Transparente, 1957, Las Buenas Consciencias, 1959, Aura, 1962, La Muerte de Artemio Cruz, 1962, Cantar de Ciegos, 1964, Zona Sagrada, 1967, Cambio de Piel, 1967, Cumpleaños, 1969, La Nueva Novela Hispanoamericana, 1968, El Mundo de José Luís Cuevas, 1969, Todos los Gatos son Pardos, 1970, La Casa con Dos Puertas, 1970, Tiempos Mexicano, 1971, Terra Nostra, 1975, Una Familia Lejana, 1980, Gringo Viejo, 1985, La Campaña, 1990, El Espejo Enterrado, 1992, Diana o la Cazadora Solitaria, 1996, Los Años con Laura Díaz, 1999, Instinto de Inés, 2001, En Esto Creo, 2002, La Silla del Águila, 2003, Contra Bush, 2004, Todas as Familias Felices, 2006, La Voluntad y la Fortuna, 2008, Vlad, 2010, La Gran Novela Latinoamericana, 2011, Federico en su balcón, 2012.

${ }^{5}$ Após a morte do autor ainda foram publicadas outras três obras póstumas que são: Pantallas de Plata(2013); Personas(2014) y Aquiles, o el guerillero y el asesino(2016).
} 
Federico en su balcón ${ }^{6}$ se identifica com o idílio na medida em que vai desenvolvendo um tom filosófico entre o narrador e seus interlocutores. A obra está dividida em quatro partes e redividida por títulos que podem ser facilmente identificados na letra do hino nacional mexicano e de sua Revolução. Este é um romance que permite dialogar com a filosofia Nietzschiana da vontade de poder, do eterno retorno, do divórcio homemnatureza e principalmente dos limites que envolvem a capacidade humana na busca de seus ideais, isto porque os diálogos estabelecem tal ritmo narrativo.

Na obra o assassinato do Presidente Solibor e em seguida o de Saúl Renania deflagra o movimento de um povo carente de líderes e de ideologia, o que é narrado na história é a revolução "da massa”, a revolução de uma população operária e rural que desacredita na efetivação da mudança social através de uma luta em que a força é desproporcional, porque no fundo, ou a qualquer momento a elite social representada na obra pode matar de fome e por repressão sangrenta uma população que já não tem ideais a não ser matar a sua fome e tentar sobreviver. Quando perdem seu líder carismático se desinteressam e ridicularizam a liderança ideológica e burguesa de Dante e de Aarón, assim o processo de mudança social é seguido pela ditadura e pelo caos, o que reflete uma aproximação histórica de um tempo ditatorial do continente americano.

A fragilidade humana dos personagens apresentados na obra impacta porque de algum modo eles também são uma caricatura de um comportamento social comum e repetitivo durante conflitos do cidadão com o Estado. Assim, a obra serve como representação de uma realidade histórica que se encontra alinhada com o romance do autor mexicano Hernán Lara Zavala e permite que este autor entre na varanda de Carlos Fuentes e trave com ele o diálogo sobre a "defasagem de tempo" a que estamos submetidos dentro e fora da literatura.

\section{Carlos Fuentes: leitor de Hernán Lara Zavala}

Dentre as várias possibilidades oferecidas por sua obra jornalística, que é enorme, e majoritariamente ligada à reflexão sobre os escritos literários, análises sobre o imperialismo americano e suas intrincadas relações com o

${ }^{6} \mathrm{Na}$ tradução para a língua portuguesa. 
México, ou sobre os anos de 1960, ou 1968 como na obra: Paris, Praga e México. O recorte escolhido foi: "El Yucatán de Lara Zavala», texto de Carlos Fuentes que traz uma leitura do romance de Zavala, e com este artigo publicado no El Diario Reforma do México, em 7 de abril de 2008, Fuentes ganhou o Prêmio González Ruano de Jornalismo. Trata-se de prêmio de jornalismo espanhol, Fuentes foi o trigésimo quarto laureado e o primeiro latino-americano a ser agraciado.

É interessante observar que as leituras que Fuentes fazia dos romances eram fecundas, vez que buscava as múltiplas temporalidades do romance, sempre relacionadas com certa cosmovisão histórico-cultural. No discurso proferido ao receber o prêmio, há uma reflexão complementar, acerca da dualidade, Literatura e Jornalismo, quando ele afirma "são ofícios que se interpenetram e curiosamente mudam de lugar".

Peninsula, Peninsula ${ }^{7}$ é um romance que trata dos conflitos da região da Península de Yucatán, por volta de 1847, lugar onde explode a chamada Guerra das Castas. O narrador, José Turissa, escritor Yucatano, funcionário público que ao mesmo tempo em que narra, no século XXI, um fato histórico do século XIX, reflete acerca do tempo. O narrador é "casado" com uma viúva, Lorenza, com quem desenvolve toda uma preocupação com a narrativa objetiva dos fatos históricos e ao mesmo tempo comenta a bibliografia existente sobre esses fatos. Esse narrador traz à tona a questão das análises de grandes fatos históricos e suas alterações e ressignificações no transcurso do tempo.

O artigo de Fuentes em questão é "El Yucatán de Lara Zavala»", ali, começa discorrendo sobre as relações entre História e Literatura. Retoma vários casos da história da literatura recordando: a Revolução Francesa não teve romancistas imediatos teve que esperar por Balzac e Stendhal; Guerra e Paz de Tolstoï, como sabemos, narra a invasão do exército de Napoleão Bonaparte à Rússia, tempos depois do ocorrido. Assim afirma que dentre muitos outros aspectos relevantes, há um aspecto interessante e capital que ele chama de "defasagem de tempo". A História da invasão francesa à Rússia foi escrita no calor dos acontecimentos e sob a influência da paixão nacionalista, logo após o acontecido, em 1812. Dentro deste contexto a nação

\footnotetext{
7 Zavala, Hernán Lara. Península, Península, Alfaguara, México, 2008, 368pp.

${ }^{8}$ https://www.elsiglodetorreon.com.mx/noticia/342936.el-yucatan-de-lara-zavala.html
} 
russa se sentiu ultrajada porque o seu exército não foi capaz de destruir completamente o exército inimigo e sobretudo seu comandante, Napoleão Bonaparte. Esses descontentamentos acarretaram julgamentos e injustas condenações à morte.

A defasagem de tempo representaria uma separação epistemológica entre o objeto histórico e o objeto literário. Dessa forma, quanto ao romance: ele foi lentamente publicado em partes entre 1865 e 1869. Observa-se, portanto, que objeto literário, no caso de Tolstoï, permitiu pelo distanciamento cronológico e pela reflexão da leitura de documentos de época apresentar o fato histórico sobre outras bases, que por um lado esclarecem melhor os fatos, e por outro ampliam a análise histórica e as suas relações com o tempo. Essa é uma posição clássica do ponto de vista teórico, que também pode ser exportada para a separação epistemológica entre o jornalismo e a literatura, desde que o primeiro seja entendido como uma narrativa do presente e a literatura como uma narrativa em defasagem com o passado.

Em $A$ arte do Romance, Kundera sugere que a criação literária nasce por uma metáfora do riso de Deus, entendido a partir de um velho ditado judeu que afirma que enquanto os homens pensam Deus ri. São as macaquices humanas, que provocam o eco do seu riso no tempo e este é captado, em um observatório imaginário, por aquele que cria e escreve o romance. Um processo com tamanhas possibilidades de procedimentos não pode estar limitado por regras conceituais restritivas. Essa falta de restrições estabelece as possibilidades para que a arte romanesca seja transgressiva toda vez que cria. Desta forma, entende-se que aquilo que deseja Fuentes é, sobretudo, exaltar a transgressividade do autor e de sua obra, o criador literário é receptor das tradições e um destruidor de modelos construídos pelo tempo.

Hernán Lara Zavala. uno de los escritores mexicanos más cultos v reticentes. establece de arranaue la actualidad de lo aue narra gracias a un novelista (; el prodio Lara Zavalap) aue se sienta a escribir la novela aue estamos levendo: Península. cuvo tema es la Guerra de las Castas aue asoló a Yucatán en 1847. Lara Zavala se inscribe así en la gran tradición. la tradición fundadora de Cervantes. donde la novela de Ouiiote v Sancho coincide con la actualidad de España. el pasado evocado por las locuras del hidalgo. el género vicaresco (Sancho) en diálogo con el édico (Ouiiote) v los estilos morisco. bizantino. amoroso v bastoral introducidos bara darle a la novela su carta de ciudadanía: la diversidad genérica. 
(https://www.elsiglodetorreon.com.mx/noticia/342936.e l-yucatan-de-lara-zavala.html)

O advento da era moderna deu a ciência e a tecnologia papéis hegemônicos, fruto da capacidade de pensar metodologicamente, segundo regras cada vez mais restritivas. O romance, que num certo sentido, também é uma invenção da modernidade com suas dificuldades restritivas é também uma racionalidade moderna oposta ao mundo contemporâneo da ciência e da técnica.

A ideia moderna de método produz uma visão de mundo cercado de certezas, talvez por isso hoje em dia se confunda filosofia com ideologia. Pouco a pouco, pensar deixa de ser duvidar, para se transformar na expressão concludente de verdades transitórias. Curiosamente esse novo espaço moderno, onde o pensar é uma afirmação e não mais dúvida, deixa a forte impressão de que não pode haver mais espaço para a afirmação da maiêutica socrática: só sei que nada sei. Os recursos estéticos fazem com que o autor reflita sobre a dúvida, trazendo assim o pensar clássico para a internalidade do romance.

Quando Carlos Fuentes afirma a cultura de Zavala, ele está chamando atenção ao mesmo tempo para a sua infinita possibilidade de fruição criativa. A fruição, conceito kantiano que fala da capacidade crescente de reflexões comparativas, pode manifestar-se tanto na criação literária, quanto na recepção. Um Zavala culto permite entender as várias possibilidades reflexivas deste romancista, isto porque imagina um narrador no presente criativo (2008) que fala de um fato histórico, ocorrido no século XIX, Yucatán, 1847. A criação fruitiva autoriza sua narrativa a introduzir reflexões sobre a historiografia do fato e complementar o acontecimento histórico com as suas próprias reflexões enquanto narrador. A delicadeza da leitura de Fuentes revela que Península Península é um romance que pensa ${ }^{9}$.

A arte do romance não requer provas como no mundo da ciência, some-se a esse privilégio, que no mundo da ficção os tempos se confundem: passado/presente, presente/presente, futuro/passado, etc. A defasagem temporal permite ao romance se impor para além da moral, isto é, não permite que a moral externa ao romance possua algum significado. $\mathrm{O}$ fato de

${ }^{9}$ A denominação de romance que pensa está na obra A cortina de Milan Kundera, 2006, p. 67. 
Guerra e Paz ter sido escrito bem depois do tempo histórico possibilitou, entre tantas outras coisas, a Tolstoï mostrar que a retirada do exército de Napoleão só podia ser acompanhada pelo exército russo, as condições climáticas (temperaturas extremamente baixas) impediam o combate, não houve falta de coragem do exército russo, os militares só podiam acompanhar a retirada do exército invasor em uma espécie de ballet mórbido, com muitas mortes de ambos os lados. A mensagem de Tolstoï só pode ser recebida ou compreendida por esse jogo imaginativo do tempo que desconstrói fábulas realistas.

Para Fuentes, Zavala mostra esta mesma problemática com nuanças ainda mais claras que Tolstoï. O efeito estético da narrativa leva o leitor a se transformar na medida em que pensa e frui a obra. Ele consegue isso porque mostra o papel, a importância e a relevância daquele que narra, o que naturalmente provoca impensável associação entre o fato histórico com um lugar de fala definido, gerando assim cores diversas e ao mesmo tempo impedindo a redução lógico-científica.

Claro que há moral em um romance, mas esta só pode ser interna ao próprio romance; o que equivale a dizer que uma narrativa literária que não faz seu leitor fruir é imoral. A arte do romance deve reagir a qualquer moral externa que tente julgá-la. Não há regras para a criação romanesca, assim sendo, Fuentes está mostrando que ainda que exista a separação disciplinar entre História e Literatura, a transgressão é possível porque esta é da essência da arte. Se a análise histórica é metodológica e objetiva, porque é ciência, o romance é diverso e subjetivo porque é arte. Ao invés de pontual e precisa, a prosa literária é ao mesmo tempo genérica e variada, o que permite a emergência da representação da expressão de certa pluralidade cidadã. A História é séria, a arte do romance é brincadeira levada a sério.

El tránsito de Lara Zavala de su irónica actualidad de narrador a la materia narrada. le permite presentar ésta. la Guerra de Castas en Yucatán. con una variedad de ritmos $\mathrm{v}$ temas aue no sólo la salvan de cualauier sospecha de didactismo. sino aue enriauecen lo aue va sabíamos con el tesoro de lo aue podemos imaginar. Aauí se dan cita no sólo los hechos v personaies históricos. los gobernadores Méndez v Barbachano. los líderes mavas Pat v Chi v las contrastantes sociedades de la elite criolla $\mathrm{v}$ las comunidades indígenas. Están también los mercaderes locales v los "gachudines": el doctor Fitzdatrick v su leal (demasiado leal) perro Pompevo. Están los clérigos v también los monaguillos v sacristanes indios aue los asesinan. Está el "México v sus revoluciones" de Iosé María Luis Mora. en toda su caótica simultaneidad. Está, protagónica, la tierra yucateca, las 


\begin{abstract}
llanuras blancas sin vegetación. brillando dolorosamente. Están el sol. los laureles. el fresco. Están el mediodía de Dlomo. el bochorno. Están las hierbas ... evocadas con una minuciosidad amorosa aue revela la formación literaria inglesa de Lara Zavala. sobre todo la lección de D. H. Lawrence. la capacidad de ubicar la pasión en la naturaleza.

(https://www.elsiglodetorreon.com.mx/noticia/342936.e l-yucatan-de-lara-zavala.html)
\end{abstract}

Importante apontar que no limiar da modernidade, a paixão é imediatamente separada da razão por Descartes, de forma que o mundo da ciência e da técnica não contempla a paixão, o sentimento, ou a poesia da vida. Então só a transgressividade do romance pode "ubicar" paixão e natureza. Zavala descreve os personagens históricos com um olhar irônico de quem está no século XXI, isto permite ao narrador o serio ludere ${ }^{i o}$, um exercício do gesto criativo e transgressivo que permite que a narrativa romanesca seja não ideológica e assim se transforme em filosófica, genérica, em que o ponto não é a questão, mas sim a totalidade incompleta abordada em todas as suas possibilidades fruitivas.

O discurso científico histórico é um discurso objetivo porque é metodológico. Já a narrativa literária é diletante, fala de uma totalidade que não é mais que uma aproximação temporária e relativa da verdade. Se há metodologia na criação literária, ela deve ser própria a um autor ou a um romance, de forma geral tem que ser aceita no plural em suas diversas possibilidades de leitura, portanto no extremo oposto da singularidade da ciência. Como não pode aceitar a metodologia singular e redutivista da ciência a arte romanesca permite-se ser transgressiva.

Poraue la magia de la tierra contiene la muerte de la tierra. El cabecilla rebelde Chi es asesinado por el amante de su muier. Anastasio. La rebelión vierde (en todos los sentidos) la cabeza. $\mathrm{v}$ el presunto comerciante muerto. Genaro. reaparece a reclamar a su muier casada sólo bara ser devuelto a otra muerte: el anonimato. el silencio. como el Coronel Chabert de Balzac, "muerto en Eylau", sin derecho a la resurrección.

(https://www.elsiglodetorreon.com.mx/noticia/342936.e l-yucatan-de-lara-zavala.html)

\footnotetext{
${ }^{10} \mathrm{O}$ serio ludere mostra que a necessidade de uma obra ser interpretada não se esgota. Este termo é compreendido a partir da leitura de Gadamer (1999), sobre a interpretação da expressão ver: Barroso e Barroso Filho, 2013.
} 
No romance de Zavala, o lugar rígido e metodológico da História dá lugar aos fatos que sem a clássica necessidade metodológica da prova, se permitem representar e descrever os fatos associados as suas emoções. $\mathrm{O}$ pensar como arte parte da emoção sensitiva, o que faz com que a dimensão humana fique enaltecida e explicitada. O historiador precisa legitimar o seu discurso através de provas e/ou documentos comprobatórios das suas afirmações. Obviamente que a ciência quer uma racionalidade redutiva e organizada com clareza de significado. Todavia, no mundo do romance tem grande relevância os múltiplos significados, porque estes representam o desenvolvimento sensível do conhecimento da cultura em geral.

Sob o pretexto de falar de Península, Península de Lara Zavala, Fuentes explora a relação história/literatura porque quer deixar evidente que a ficção tem um papel transcendental que vai muito além do fato histórico. A Guerra das Castas em 1847 narrada por Zavala é sublime não é cronologicamente linear, está envolta entre véus que eliminam a objetividade e a clareza, por isso incitam o leitor a pensar e a fruir.

Em Penísula, Península, o contador de histórias cruza o Charco falando do papel da ficção no mundo sério, acaba virando jornalista, mas conserva a imaginação. O gesto jornalístico de Fuentes quer mostrar que sua análise do romance de Zavala não procura evocar a existência de conteúdos estéticos clássicos da ficção tais como paixão, tristeza, vontade ou ambição. O que Carlos Fuentes quer é trazer para o centro da notícia a história modesta que quase sempre se perde nas páginas de cultura dos grandes jornais. Fazer uma análise sensível, em toda a sua grandeza e importância, para revelar matizes, cores e odores novos a ponto de esclarecer o mundo das verdades.

Fuentes tem a convicção de que a literatura não figura entre as grandes manchetes da imprensa, mas muitas matérias de jornais se perderam em páginas de obras literárias, sejam elas em verso ou em prosa.

\section{Na varanda com Fuentes pensando em Zavala}

Utilizar da metáfora com o último dos romances de Fuentes, imaginemo-nos entre dois balcões, um do jornalista e outro do escritor, ambos se completam, interagem em uma fenomênica dialética. A tensão essencial existente entre os dois produz uma curiosa ontologia, já que o jornalista 
desvenda o romancista, e o romancista instiga ao jornalista. A angústia do futuro da condição humana, subtraí o otimismo e a preparação do futuro.

A crítica ao idílio se revela uma poderosa e contemporânea Metafísica, que libera a condição humana ao conflito. O mundo sério é o mundo do jornalismo, mas que enfrenta dificuldades dadas pelas relações de poder e os interesses momentâneos, o que torna difícil a emergência de um solo cultural que afirme a verdade. Isto se dá em entrelinhas e meias palavras, por isso o jornal não coloca a análise do romance no seu primeiro caderno, mas apenas nas páginas de cultura. Já o romance coloca a vida em evidência, mostra que a condição humana, por todas as suas incompletudes, estará sempre como Quixote e Sancho lutando contra intermináveis moinhos de vento.

Retomemos o primeiro ponto de nossa apresentação sobre Carlos Fuentes e sua amizade com Milan Kundera. Na medida em que permite o diálogo entre as culturas, o modo como se estabelece o diálogo entre Fuentes e Kundera nos revela sobremaneira o fato de ser o romance, por si só, um elemento trans - nesse caso específico transcultural e transacional. Quando aproxima e faz dialogar a Europa Central de Kundera e a América Latina de Fuentes o romance desterritorializa o nacional. Tal percepção se acentua quando damos conta do segundo aspecto trazido para o centro do debate, aquele que trata do olhar do latino-americano sobre o mundo romanesco kunderiano.

O encontro destes dois autores, geográfica e culturalmente distantes, possibilita a Fuentes esclarecer uma questão teórica relevante, a desterritorialização do nacional nos romances, permite mostrar na singularidade de cada narrativa literária a dimensão universal da condição humana. O artigo jornalístico de Fuentes sobre Zavala busca esse universal no interior da Guerra das Castas e é ajudado nesta tarefa pelo estilo narrativo do autor de Península, Península.

A partir da leitura de Fuentes sobre Zavala, a qual se junta o estudo deste primeiro a obra de Milan Kundera é possível situar o significado mais importante do discurso de Fuentes na recepção do Prêmio González Ruano de Jornalismo. Nele encontramos esclarecimentos sobre os não ditos interessantes do artigo e que só podem ser compreendidos cotejando o seu discurso com a questão estética da arte. Afirma Fuentes: "Para que la ficción sea ficción, la prensa debe ser verdad. Cuando la novela convierte la verdad en 
ficción, es fiel a sí misma, pero cuando la prensa convierte la verdad en ficción, resulta increíble y condenable". (Fuentes, 2008) A crítica à estética do idílio retira a possibilidade de Carlos Fuentes, seja ele o jornalista, seja ele o escritor, de possuir um olhar apaziguador. Há neste gesto uma inequívoca postura crítica a todos os idílios possíveis, passados e futuros.

Neste sentido Península, Península representa a possibilidade literária de debater o tempo, seja o passado quando foi presente, seja o presente enquanto presente mexicano. A Guerra das Castas foi um dia presente, naquele tempo passado, seus atores agiram em conformidade com o ar daquele tempo. A narrativa do século XXI sobre o fato histórico do século XIX revisita o passado a partir de um olhar do seu presente, neste gesto de ficção há um elemento transformador: a imaginação razoável.

A análise que faz Fuentes do livro de Zavala junta a leitura simples do livro, uma cosmovisão, que é representada pelas informações gerais do mundo da Comunicação e da História. Isto ocorre porque as lições da Grande História não foram capazes de fazer do México um estado mais igualitário, mesmo se paradoxalmente o mundo da mídia noticia a expansão e o progresso do México.

\section{Conclusão}

Um questionamento importante da narrativa de Federico em su balcón acerca da relação homem tempo se faz na parte treze da fala de Federico: "Podemos ser contemporâneos de todos os seres humanos? Sim graças ao pensamento, ou a obra de arte, a literatura” (FUENTES, 2012, p. 80). $\mathrm{O}$ que demonstra que a arte fala da contemporaneidade da existência- como um individuo longe do outro e por isso vivendo em outro tempo, incorpora a outra pessoa que também tem seu tempo, deixam de ser estranhos voltam a ser contemporâneos no sentido de existir ao mesmo tempo.

É nesse sentido que o autor pode se revelar em sua varanda, em seu aconchego em meio aos amigos num processo de retomada dos desdobramentos complexos da leitura, das digressões que avançam sobre temas tão próprios do sentido humano de se viver a revolução e a transformação do mundo através da escrita do dia a dia. 


\section{Referências}

BARROSO FILHO, W.; BARROSO, M. V. Epistemologia do Romance: Uma proposta metodológica possível para a análise do romance literário. Brasília, 2013. Disponível em: http://epistemologiadoromance.blogspot.com.br/ Acesso em: julho de 2017.

FUENTES, Carlos. Geografia do romance. Trad. Carlos Nougué. Rio de Janeiro: Rocco, 2007.

FUENTES, Carlos. Em 68: Paris, Praga e México. Trad. Ebréia de Castro Alves. Rio de Janeiro: Rocco, 2008.

FUENTES, Carlos. Federico en su balcón. Madrid: Alfaguara, 2012.

GIRONDE, M. Carlos Fuentes: entre Hispanité et americanité. Paris: L'Harmattan, 2011.

HOBSBAWM, Eric J. Era dos Extremos: o breve século XX. Trad. Marcos Santarrita. São Paulo: Cia das Letras, 1995.

KUNDERA, Milan. Os testamentos traídos. Trad. Teresa Bulhões C. da Fonseca e Maria Luiza N. da Silveira. Rio de Janeiro: Nova Fronteira, 1994.

KUNDERA, Milan. A cortina. Trad. Teresa Bulhões C. da Fonseca. São Paulo: Cia das Letras, 2006.

KUNDERA, Milan. O livro do Riso de do esquecimento. Trad. Teresa Bulhões C. da Fonseca. São Paulo: Licença editorial para o Círculo do Livro por cortesia da Editora Nova Fronteira.

KUNDERA, Milan. A arte do romance. Trad. Teresa Bulhões C. da Fonseca e Vera Mourão. Rio de Janeiro: Nova fronteira, 1988.

ZAVALA, Hernán Lara. Península, Península. Madrid: Alfaguara, 2008.

Recebido em 30 de abril de 2018.

Aceito em 28 de maio de 2018. 